American Journal of Pharmaceutical Education 2020; 84 (2) Article 7561.

\title{
RESEARCH
}

\section{Factors Associated with Student Pharmacists' Academic Progression and Performance on the National Licensure Examination}

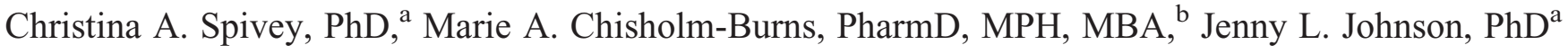 \\ ${ }^{a}$ University of Tennessee Health Science Center College of Pharmacy, Memphis, Tennessee \\ ${ }^{\mathrm{b}}$ University of Tennessee Health Science Center College of Pharmacy, Memphis, Knoxville, Nashville, Tennessee \\ Submitted February 15, 2019; accepted June 28, 2019; published February 2020.
}

Objective. To examine predictors of Doctor of Pharmacy (PharmD) students' on-time graduation, dismissal from pharmacy school, and scores on their first attempt at taking the North American Pharmacist Licensure Examination (NAPLEX).

Methods. A retrospective review of student records for the graduating classes of 2015-2018 at a college of pharmacy was performed. Data on the following were collected: student demographics/ characteristics (age, gender, race/ethnicity, financial need), having an undergraduate degree, undergraduate science grade point average (GPA), Pharmacy College Admission Test composite score percentile, pharmacy school GPAs for the didactic portion of the curriculum, Pre-NAPLEX score, on-time graduation from pharmacy school, dismissal from pharmacy school, and outcome (pass/fail) of first-attempt at taking the NAPLEX. Binary logistic regression analysis was conducted.

Results. Of the 657 students whose records were included in the study, the majority were female (60\%) and non-Hispanic white (70\%). Higher first-year GPA was associated with increased likelihood of ontime graduation, while increased age and having an undergraduate degree were associated with a decreased likelihood of on-time graduation. A higher first-year GPA was associated with decreased likelihood of being dismissed from pharmacy school. Appearing before the Academic Standing and Promotion Review Committee for unsatisfactory academic performance was associated with decreased likelihood of passing the NAPLEX.

Conclusion. First-year pharmacy school GPA is a critical predictor for student pharmacists in terms of on-time graduation and dismissal, and may have consequences for later NAPLEX outcome. Pharmacy schools should closely monitor students' performance during the first year and provide support to students experiencing academic difficulties.

Keywords: academic progression, dismissal, grade point average, North American Pharmacist Licensure Examination, student pharmacists

\section{INTRODUCTION}

Schools and colleges of pharmacy aim to educate students and prepare them for a broad range of careers within the pharmacy profession. The success of programs is directly tied to the ability of students to succeed in their didactic coursework and experiential rotations, and to make timely progress through the Doctor of Pharmacy (PharmD) program. There is a growing awareness among pharmacy schools of the need to improve students' academic progression to increase higher on-time graduation rates and possibly higher first-time pass rates on the North American Pharmacist Licensure Examination

Corresponding Author: Christina A. Spivey, University of Tennessee Health Science Center College of Pharmacy, 881 Madison Ave., Ste 258, Memphis, TN 38163. Tel: 901-4487141. Fax: 901-448-7053. Email: Cspivey3@uthsc.edu
(NAPLEX). ${ }^{1-3}$ Significant effort has been applied to predicting which students may not progress through the program as expected and to identifying stumbling blocks that may be inadvertently placed along the path to graduation.

Among the factors that can predict students' failure to progress before they enter a pharmacy program are standardized test scores, including both the American College Test (ACT) and Pharmacy College Admission Test (PCAT) scores. ${ }^{1,4}$ Additionally, a previous study found that the PCAT composite score was associated with NAPLEX performance (ie, scores), but explained only a small percentage of the variance in NAPLEX scores. ${ }^{5}$ Moreover, this study limited its analysis to prepharmacy factors and did not consider the influence of students' pharmacy school academic performance on NAPLEX 


\section{American Journal of Pharmaceutical Education 2020; 84 (2) Article 7561.}

scores. Additionally, prepharmacy grade point average (GPA), particularly grades in undergraduate biology and chemistry courses, is a predictor of performance in the PharmD program. ${ }^{1,4,6-8}$ Some previous studies also found that earning a degree prior to entering pharmacy school is beneficial. ${ }^{6.9,10}$

After being admitted to a pharmacy program, the early period of didactic study is the most difficult for students as they grapple with the scope of new information, problems with time management and study strategies, and preparing for tests. ${ }^{11}$ A student is more likely to make an unsatisfactory grade of D or F during the first two years of a PharmD program, leading to remediation and possible failure to progress. ${ }^{4}$ In particular, indicators of poor performance in the first semester may be predictors for student success within pharmacy programs. A low grade on the first examination, a low overall GPA in the first integrated science course, or a low cumulative GPA in the first semester is associated with a student being less likely to graduate on time, more likely to remain in the bottom GPA quartile of the class throughout their training, and less likely to pass the NAPLEX on their first attempt. ${ }^{2,3}$ Older students in pharmacy school appear to struggle academically more than younger students and are more likely to have lower GPAs and lower NAPLEX scores. ${ }^{5,12}$

Disruptions in academic progression may have serious consequences for affected students. Students who are dismissed from pharmacy school may face the loss of tuition dollars, and may also need to reevaluate their educational and career goals. For example, dismissed students who entered pharmacy school prior to receiving an undergraduate degree may need to consider returning to their undergraduate studies. Students who must remediate coursework or retake courses, whether or not they are delayed in their pharmacy school progression, may have ongoing challenges. The goal of remediation, ie, repeating all or part of one or more courses, is to allow students to get a better grasp of the information and move forward in the PharmD program. Unfortunately, this seems to be most effective for students who have done poorly in only one or two courses. ${ }^{13}$ While remediation may help some students to complete their degree requirements, those students may be less likely to pass the NAPLEX on their first attempt. ${ }^{14}$ Previous studies found that, compared to a national first-time NAPLEX pass rate of $87.95 \%$ for 2017 graduates, students with even just one unsatisfactory grade of a D or F during the pharmacy curriculum had a first-time pass rate of $77 \%$, and students who had delayed graduation (ie, took more than four years to complete the PharmD program) had a pass rate of $75 \%{ }^{14,15}$
Given the evolution of pharmacy education and the critical effects of academic progression delays or disruptions on student outcomes, including NAPLEX performance, ongoing evaluation of proposed predictors of on-time progression as well as disruptions is needed. This study therefore aimed to identify predictors of on-time progression and delays or disruptions in academic progression that may inform strategies to improve student outcomes. More specifically, the objective of this study was to examine student demographics and characteristics, pre-pharmacy factors, and pharmacy school performance indicators as possible predictors of on-time graduation/ progression through a PharmD program, dismissal from pharmacy school, and first-attempt NAPLEX outcome.

\section{METHODS}

A retrospective review of records of the graduating classes of 2015, 2016, 2017, and 2018 at the University of Tennessee Health Science Center College of Pharmacy (UTCOP) was performed. The college has a four-year PharmD program. All students in these classes were eligible for inclusion, excluding students who voluntarily withdrew from the college. Withdrawals were excluded as these decisions may not have been related to academic performance, and a better understanding of academic performance and progression is the premise of this study. Data were collected through a review of student records in spring 2019. The study was approved by the University of Tennessee Health Science Center Institutional Review Board.

The following data were collected from student records and included as independent variables: age at graduation; race/ethnicity (classified as non-Hispanic white or minority); gender; whether or not the student had a four-year undergraduate degree; financial need designation (classified as less than high or high based on cost of attendance minus a student's estimated financial contribution and minus other sources of financial aid such as scholarships, as determined by the Financial Aid Office of the University of Tennessee Health Science Center); PCAT composite percentile; undergraduate science GPA at admission; and first-year (P1), second-year (P2), and third-year (P3) fall GPA, which represents the didactic portion of the curriculum at the college. We focused on GPAs from the didactic portion of the pharmacy curriculum because that is the time period in which students were most likely to experience academic difficulties. Two additional factors were included as independent variables in the NAPLEX analysis: Pre-NAPLEX score and appearance before the UTCOP's Academic Standing and Promotion Review Committee. Students at UTCOP take the 


\section{American Journal of Pharmaceutical Education 2020; 84 (2) Article 7561.}

Pre-NAPLEX during the P4 year, with the exception of the class of 2015, which took the Pre-NAPLEX in the P3 year. An appearance before the review committee was indicative of unsatisfactory academic performance and was required when students made two grades of less than a C- or if their GPA was below a certain level. Based on the review committee's evaluation, the student may have been required to repeat a course(s) or an entire semester or year, or may have been dismissed from the college.

The outcome (dependent) variables were as follows: on-time graduation or progression (within four years); whether a student was dismissed because of poor academic performance; and whether a student was successful in their first attempt at passing the NAPLEX.

Data analysis was performed using SPSS Statistics 25.0 (IBM, Armonk, New York). Student demographics/ characteristics and performance indicator data (ie, GPAs, PCAT Composite, Pre-NAPLEX score, on-time graduation, dismissal, NAPLEX first-attempt outcome of pass or fail) were summarized as descriptive statistics (frequencies for categorical variables, means and standard deviations for continuous variables). Binary logistic regression analysis was conducted to determine the effects of student demographics and characteristics (age, gender, financial need, race/ethnicity, undergraduate degree), undergraduate science GPA, PCAT composite percentile, and pharmacy school didactic GPAs as predictors of ontime graduation, being dismissed from pharmacy school, and NAPLEX first-attempt outcome of pass or fail. Analysis of NAPLEX outcome also included PreNAPLEX score and appearance before the Academic Standing and Promotion Review Committee as independent variables. Appearance before the committee was not included in the logistic regression analyses for on-time graduation and being dismissed from pharmacy school because all students who experienced delays in progression for academic reasons or were dismissed from pharmacy school had to appear before the committee. To conduct each regression analysis, variables were entered in one block simultaneously. The a priori significance level was .05.

\section{RESULTS}

A total of 657 students from the classes of 2015, 2016, 2017 and 2018 were included in the study. The majority of the sample were female $(60 \%)$ and nonHispanic white $(70 \%)$. Two percent of the students had been dismissed from the college, and $92 \%$ had graduated on time. Of 611 students who signed a consent form to release their individual NAPLEX score to the college, 586 $(96 \%)$ had passed on their first attempt. A summary of the demographics/characteristics and performance indicator variables for the sample is presented in Table 1.

The result of the logistic regression model for ontime graduation was significant (chi-square $=116.7$, $p<.001$; Table 2). The model explained $49.4 \%$ (Nagelkerke $\mathrm{R}^{2}$ ) of the variance in on-time graduation and correctly classified $96.2 \%$ of cases. Having a higher P1 GPA was significantly associated with a greater likelihood of on-time graduation, while increased age and having an undergraduate degree (OR: 0.16, 95\% CI: 0.04-0.65) were significantly associated with a decreased likelihood of on-time graduation. For each unit increase in P1 GPA, a student's odds of on-time graduation increased by a factor of 120. For each one-year decrease in age, the odds of graduating on time increased by a factor of 1.2 (calculated as the inverse of the odds ratio for age, $1 / 0.82=1.2$ ). The odds of graduating on time were 6.3 times higher for students who did not have an undergraduate degree compared to students who did have an undergraduate degree (calculated as the inverse of the odds ratio for undergraduate degree, $1 / 0.16=6.3$ ). No other variables in the model were significant. For point of reference, students who graduated on time compared to those who did not had a mean (SD) P1 GPA of $3.2(0.4)$ vs $2.4(0.5)$, respectively, and mean (SD) age of 27.5 years $(2.8)$ versus 31.6 years (7.1), respectively. Finally, $65 \%$ of students who graduated on time had earned an undergraduate degree before entering the PharmD program, while $80 \%$ of students who did not graduate on time had earned an undergraduate degree.

The logistic regression model for dismissal from pharmacy school for academic reasons was significant (chi-square $=83.4, \quad p<.001$; Table 3). The model explained $67.9 \%$ (Nagelkerke $\mathrm{R}^{2}$ ) of the variance in the dismissed outcome, and correctly classified $99.2 \%$ of cases. Higher P1 GPA was significantly associated with decreased likelihood of being dismissed from pharmacy school for academic reasons. For each unit increase in P1 GPA, the odds of being dismissed from pharmacy school decreased by a factor of 1000 . No other variables in the model were significant. For point of reference, students who were dismissed from pharmacy school for academic reasons compared to those who were not had a mean (SD) P1 GPA of 1.9 (0.5) vs 3.2 (0.5), respectively.

The logistic regression model for passing the NAPLEX on the first attempt was significant (chisquare $=70, p<.001$; Table 4). The model explained $37.7 \%$ (Nagelkerke $\mathrm{R}^{2}$ ) of the variance in on-time graduation, and correctly classified $96.5 \%$ of cases. Appearing before the review committee was significantly associated with decreased likelihood of passing the NAPLEX (OR: 0.22 ; $95 \%$ CI: $0.06-0.77$ ). The odds of passing the 
Table 1. Characteristics and Performance Indicators of Student Pharmacists Included in a Retrospective Study to Identify Factors Associated With Academic Progression and Performance on the Licensure Examination

\begin{tabular}{|c|c|}
\hline & Student Pharmacists $(\mathrm{N}=657)$ \\
\hline Mean Age at Graduation (SD) & $27.8(3.48)$ \\
\hline \multicolumn{2}{|l|}{ Class } \\
\hline $2015, \mathrm{n}(\%)$ & $178(27.1)$ \\
\hline $2016, \mathrm{n}(\%)$ & $154(23.4)$ \\
\hline $2017, \mathrm{n}(\%)$ & $163(24.8)$ \\
\hline $2018, \mathrm{n}(\%)$ & $162(24.7)$ \\
\hline \multicolumn{2}{|l|}{ Gender } \\
\hline Female, n (\%) & $391(60)$ \\
\hline Male, n (\%) & $266(40)$ \\
\hline \multicolumn{2}{|l|}{ Financial Need } \\
\hline Less than High, n (\%) & 405 (61.6) \\
\hline High, n (\%) & $239(36.4)$ \\
\hline Missing, n (\%) & $13(2)$ \\
\hline \multicolumn{2}{|l|}{ Race/Ethnicity } \\
\hline White/Non-Hispanic, n (\%) & 458 (69.7) \\
\hline Minority, n (\%) & $195(29.7)$ \\
\hline Missing, n (\%) & $4(0.6)$ \\
\hline \multicolumn{2}{|l|}{ Undergraduate Degree? } \\
\hline No, n (\%) & $222(33.8)$ \\
\hline Yes, n (\%) & $428(65.1)$ \\
\hline Missing, n (\%) & $7(1.1)$ \\
\hline Mean PCAT Composite Percentile (SD) & $66.8(19.19)$ \\
\hline Mean Undergraduate Science GPA (SD) & $3.28(0.44)$ \\
\hline Mean Pharmacy School Year 1 GPA (SD) & $3.14(0.51)$ \\
\hline Mean Pharmacy School Year 2 GPA (SD) & $3.14(0.43)$ \\
\hline Mean Pharmacy School Year 3-Fall & $3.32(0.42)$ \\
\hline Semester GPA (SD) & \\
\hline Mean Pre-NAPLEX Score & $82.9(19.53)$ \\
\hline \multicolumn{2}{|l|}{ On-time Graduation } \\
\hline No, n $(\%)$ & $52(8.0)$ \\
\hline Yes, n (\%) & $605(92)$ \\
\hline \multicolumn{2}{|l|}{ ASPR } \\
\hline No, n $(\%)$ & $576(87.7)$ \\
\hline Yes, n (\%) & $81(12.3)$ \\
\hline \multicolumn{2}{|l|}{ Dismissed from Pharmacy School } \\
\hline No, n (\%) & $644(98)$ \\
\hline Yes, n (\%) & $13(2)$ \\
\hline
\end{tabular}

Abbreviations: ASPR $=$ Academic Standing and Promotion Review, GPA= grade point average, PCAT=Pharmacy College Admission Test, NAPLEX $=$ North American Pharmacist Licensure Examination

NAPLEX on the first attempt were 4.6 times greater for students who did not appear before the review committee compared to students who did appear before the review committee (calculated as the inverse of the odds ratio for appearance before the Academic Standing and Promotion Review Committee, $1 / 0.22=4.6$ ). No other variables in the model were significant. For point of reference, of the 25 students who did not pass the NAPLEX on their first attempt, $52 \%$ appeared before the committee, while only $9 \%$ of students who passed the NAPLEX on their first attempt appeared before the committee.

\section{DISCUSSION}

We examined various student demographics and characteristics, pre-pharmacy factors, and pharmacy school performance indicators to determine whether they were predictors of students' on-time graduation or progression, dismissal from a PharmD program, or passing the NAPLEX on the first attempt. Student pharmacists with lower P1 GPAs were less likely to graduate on time and more likely to be dismissed from pharmacy school for academic reasons. Previous studies noted similar effects, with associations between poorer 
American Journal of Pharmaceutical Education 2020; 84 (2) Article 7561.

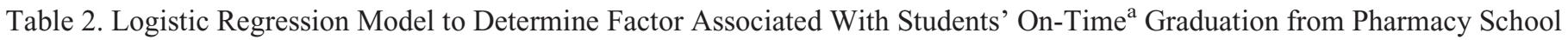

\begin{tabular}{lcccccc}
\hline $\begin{array}{l}\text { Student Characteristics/ } \\
\text { Variables }\end{array}$ & B & $\begin{array}{c}\text { Standard } \\
\text { Error }\end{array}$ & $\begin{array}{c}\text { Wald Chi } \\
\text { Square }\end{array}$ & $\begin{array}{c}\boldsymbol{p} \text { value } \\
\text { Odds }\end{array}$ & $\begin{array}{c}\mathbf{9 5 \%} \\
\text { Ratio }\end{array}$ & $\begin{array}{c}\text { Confidence } \\
\text { Interval }\end{array}$ \\
\hline Age at graduation & -0.20 & 0.05 & 14.01 & $<.001$ & 0.82 & $0.74-0.91$ \\
Gender & -0.2 & 0.47 & 0.18 & .67 & 0.82 & $0.32-2.07$ \\
High financial need & -0.18 & 0.46 & 0.16 & .69 & 0.83 & $0.34-2.05$ \\
Race/ethnicity & -0.32 & 0.49 & 0.43 & .51 & 0.73 & $0.28-1.9$ \\
Undergraduate degree & -1.84 & 0.71 & 6.01 & .01 & 0.16 & $0.04-0.65$ \\
Undergraduate science GPA & -0.59 & 0.6 & 0.97 & .33 & 0.55 & $0.17-1.8$ \\
PCAT composite percentile & -0.004 & 0.01 & 0.08 & .78 & 1.00 & $0.97-1.02$ \\
Pharmacy school year 1 GPA & 4.79 & 0.81 & 34.6 & $<.001$ & 120 & $24.4-591.41$ \\
Pharmacy school year 2 GPA & 0.27 & 0.83 & 0.11 & .74 & 1.31 & $0.26-6.71$ \\
Pharmacy school year 3-fall GPA & -1.16 & 0.77 & 2.28 & .13 & 0.32 & $0.07-1.41$ \\
\hline Abbral
\end{tabular}

Abbreviations: GPA= grade point average, PCAT = Pharmacy College Admission Test

${ }^{\text {a }}$ Within four years

${ }^{\mathrm{b}}$ Coding for categorical variables as follows: gender: $0=$ male, $1=$ female; race/ethnicity: $0=$ non-Hispanic white, $1=$ minority; undergraduate degree: $0=$ no, $1=$ yes; high financial need; $0=$ no, $1=$ yes

grades and/or lower GPA during the first one to two years of pharmacy school and delays in progression or failure to progress. ${ }^{2-4}$

In addition to the influence of P1 GPA, older students and those with an undergraduate degree were less likely to graduate on time. We speculate that older students, and to some degree students with undergraduate degrees, may have had a period of time away from higher education, and therefore may have struggled more with transitioning into a full-time, rigorous professional program course load. Older students may also have what McCall and colleagues referred to as "competing responsibilities," or greater demands on their time outside of school because of family and/or employment commitments which limit the time they can devote to their studies. ${ }^{5}$ Future studies are needed to more fully explore and understand the relationship between on-time graduation from pharmacy school and the factors of age and undergraduate degree.

Our findings further indicate that students who appeared before the Academic Standing and Promotion Review Committee, an indicator of unsatisfactory academic performance, were less likely to pass the NAPLEX on the first attempt. The majority of students who have to appear before the review committee do so during the first year of pharmacy school, further emphasizing the importance of the P1 year. Consistent with this finding, Madden and colleagues also found that students who required remediation of unsatisfactory course grades had a significantly lower NAPLEX first-time pass rate compared to students who did not need to remediate courses. ${ }^{16}$ No other independent variables were predictive of NAPLEX outcome, demonstrating the importance of remaining in good academic standing and the potential

Table 3. Logistic Regression Model to Determine Factors Associated With Students' Being Dismissed From Pharmacy School

\begin{tabular}{lcccccc}
\hline $\begin{array}{l}\text { Student Characteristics/ } \\
\text { Variables }^{\mathbf{a}}\end{array}$ & B & $\begin{array}{c}\text { Standard } \\
\text { Error }\end{array}$ & $\begin{array}{c}\text { Wald Chi } \\
\text { Square }\end{array}$ & $\begin{array}{c}\boldsymbol{p} \\
\text { value }\end{array}$ & $\begin{array}{c}\text { Odds } \\
\text { Ratio }\end{array}$ & $\begin{array}{c}\text { 95\% Confidence } \\
\text { Interval }\end{array}$ \\
\hline Age at graduation & 0.03 & 0.07 & 0.2 & .66 & 1.03 & $0.9-1.18$ \\
Gender & -0.57 & 0.99 & 0.33 & .57 & 0.57 & $0.08-3.96$ \\
Race/ethnicity & -1.03 & 1.13 & 0.83 & .36 & 0.36 & $0.04-3.27$ \\
Undergraduate degree & 0.23 & 0.96 & 0.06 & .81 & 1.26 & $0.19-8.23$ \\
Undergraduate science GPA & 0.31 & 1.12 & 0.08 & .78 & 1.37 & $0.15-12.34$ \\
PCAT composite percentile & 0.04 & 0.03 & 2.39 & .12 & 1.05 & $0.99-1.11$ \\
Pharmacy school year 1 GPA $^{\mathrm{b}}$ & -6.87 & 1.43 & 23.12 & $<.001$ & 0.001 & $0.0-0.02$ \\
\hline Abbra
\end{tabular}

Abbreviations: GPA= grade point average, $\mathrm{PCAT}=$ Pharmacy College Admission Test

${ }^{a}$ Coding for categorical variables as follows: gender: $0=$ male, $1=$ female; race/ethnicity: $0=$ non-Hispanic white, $1=$ minority; undergraduate degree: $0=$ no, $1=$ yes. Due to missing financial need data on dismissed students, high financial need was not included as a variable in this analysis ${ }^{b}$ Pharmacy School Year 1 GPA was the only pharmacy school GPA included in this analysis because all but two dismissals occurred due to performance in the first year of pharmacy school 


\section{American Journal of Pharmaceutical Education 2020; 84 (2) Article 7561.}

Table 4. Logistic Regression Model to Determine Factors Associated With Student Pharmacists Passing the Licensure Examination on Their First Attempt

\begin{tabular}{lcccccc}
\hline $\begin{array}{l}\text { Student Characteristics/ } \\
\text { Variables }^{\mathbf{a}}\end{array}$ & $\mathbf{B}$ & $\begin{array}{c}\text { Standard } \\
\text { Error }\end{array}$ & $\begin{array}{c}\text { Wald Chi } \\
\text { Square }\end{array}$ & $\boldsymbol{p}$ value & $\begin{array}{c}\text { Odds } \\
\text { Ratio }\end{array}$ & $\begin{array}{c}\mathbf{9 5 \%} \text { Confidence } \\
\text { Interval }\end{array}$ \\
\hline Age at graduation & -0.09 & 0.05 & 3.1 & .08 & 0.92 & $0.83-1.01$ \\
ASPR committee & -1.51 & 0.64 & 5.57 & .02 & 0.22 & $0.06-0.77$ \\
Gender & 0.41 & 0.5 & 0.66 & .42 & 1.5 & $0.56-4.03$ \\
High financial need & -0.43 & 0.5 & 0.73 & .39 & 0.65 & $0.25-1.73$ \\
Race/ethnicity & -0.44 & 0.52 & 0.75 & .39 & 0.64 & $0.23-1.77$ \\
Undergraduate degree & -0.27 & 0.54 & 0.25 & .62 & 0.76 & $0.27-2.18$ \\
Undergraduate science GPA & 0.46 & 0.63 & 0.54 & .46 & 1.59 & $0.46-5.47$ \\
PCAT Composite percentile & 0.03 & 0.01 & 3.47 & .06 & 1.03 & $0.999-1.05$ \\
Pharmacy school year 1 GPA & -0.47 & 0.9 & 0.27 & .6 & 0.63 & $0.11-3.62$ \\
Pharmacy school year 2 GPA & 0.99 & 0.99 & 0.99 & .32 & 2.68 & $0.39-18.62$ \\
Pharmacy school year 3-fall GPA & 1.34 & 0.89 & 2.27 & .13 & 3.83 & $0.67-22.01$ \\
Pre-NAPLEX score & .027 & 0.02 & 3.08 & .08 & 1.03 & $0.997-1.06$ \\
\hline
\end{tabular}

Abbreviations: ASPR $=$ Academic Standing and Promotion Review, GPA= grade point average, NAPLEX=North American Pharmacist Licensure Examination, PCAT $=$ Pharmacy College Admission Test

${ }^{a}$ Coding for categorical variables as follows: ASPR: $0=$ no ASPR appearance, $1=$ appeared before ASPR; gender: $0=$ male, $1=$ female; race/ ethnicity: $0=$ non-Hispanic white, $1=$ minority; $0=$ no, $1=$ yes; undergraduate degree: $0=$ no, $1=$ yes; high financial need; $0=$ no, $1=$ yes

long-term consequences for students who struggle academically.

The body of evidence accumulated in this and prior studies highlights the first year of pharmacy school as a critical time period in the education of student pharmacists. The beginning of any new professional or graduate program is highly stressful. The P1 year, in particular, marks the transition from undergraduate study (for the vast majority of students) or a break in study (for students who are going back to school after one or more years away from higher education) to more intensive professional study. Such a transition comes with a demanding course load and exposure to new and unfamiliar learning experiences. For example, introductory pharmacy practice experiences (IPPEs), which begin in the first year of pharmacy school, have been identified as a "major stressor" for student pharmacists. ${ }^{17}$ Additional first-year courses at UTCOP include Pharmacy Math, among several others. Students may therefore experience increased anxiety as they try to adapt their learning/study habits and preferences for the intensity, demands, structure, and faster pace of the professional, graduate-level environment. Students may also be juggling multiple personal roles and responsibilities (eg, spouse, parent, caregiver, employee) that they may not have had while in an undergraduate setting. ${ }^{18,19}$ These various changes and role adjustments can result in shifts in self-esteem and an increase in insecurity and stress among students. ${ }^{18}$

While coping strategies are available for students experiencing increased workload and test-induced anxiety and stress, few students take advantage of counseling offered by colleges or universities, or are even aware such programs exist. ${ }^{8,20,21}$ The help-seeking behaviors of students are directly tied to the perceived helpfulness of faculty members, and traditional teaching methods may not reach these students. ${ }^{21,22}$ The current expectation that students are able to understand their own learning needs, focus their time on particular needs, and evaluate their own academic performance may stretch the capacity of students experiencing academic difficulties. ${ }^{23}$ To address this issue, the establishment of early warning or detection systems to identify struggling students in the first year, prior to academic disruptions, could increase their chance of success within a pharmacy program. The college has implemented a version of this early warning system (triggered by examination performance) to monitor student academic performance throughout the didactic portion of the curriculum, and provide support and resources when appropriate. Mid-semester has proven to be a good time point for interventions, and provision of supplemental instruction when academic issues are identified may increase student retention and improve grades. ${ }^{8,13}$ Other mechanisms to improve student performance in the first year include tutoring services, active learning and flipped classroom approaches that boost student pharmacist confidence and understanding, formal mentoring programs in which upper-class student pharmacists provide mentorship to first-year students, and online prerequisite tutorial reviews of core science topics. ${ }^{24-26}$

This study has limitations including that the analysis was based on a population of students who completed a four-year PharmD program with a curriculum that 


\section{American Journal of Pharmaceutical Education 2020; 84 (2) Article 7561.}

entailed approximately 2.5 years of didactic coursework and 1.5 years of experiential coursework. Additionally, curricula may vary across pharmacy schools. As such, generalizability of the results may be limited to PharmD programs with like structures and curricula. Future studies should examine the consistency of the proposed predictors across programs with both similar and disparate structures and curricula. An additional limitation is that the independent variables examined in this study did not include measures of non-cognitive factors such as conscientiousness, perseverance, selfefficacy, locus of control, and resilience, which may influence student academic performance. Although each regression model explained a substantial percentage of the variance in each outcome of interest, future studies should explore the potential predictive value of noncognitive skills, in addition to those factors evaluated in this study, to develop more comprehensive models of student pharmacist academic progression and NAPLEX achievement.

\section{CONCLUSION}

This study examined student demographics/characteristics, pre-pharmacy factors, and pharmacy school performance indicators as possible predictors of on-time graduation and dismissal from pharmacy school, as well as first-attempt NAPLEX performance. In summary, the first-year pharmacy school GPA represents a critical factor for student pharmacists in terms of on-time academic progression and risk of dismissal. Age and whether a student has an undergraduate degree are also associated with on-time graduation. Unsatisfactory academic performance, particularly in the P1 year, may also ultimately effect whether a student is able to pass the NAPLEX in their first attempt. As noted in this study, appearing before a college committee because of poor academic performance is predictive of NAPLEX outcome. Colleges of pharmacy should closely monitor student performance during the first year of pharmacy school and implement strategies to support students who are experiencing academic difficulties in improving their academic performance.

\section{ACKNOWLEDGMENTS}

Marie Chisholm-Burns serves on the board of directors for ACPE. This manuscript does not represent ACPE or the board's opinions or views.

\section{REFERENCES}

1. Houglum JE, Aparasu RR, Delfinis TM. Predictors of academic success and failure in a pharmacy professional program. Am J Pharm Educ. 2005;69(3):Article 43.
2. Alston GL, Lane D, Wright NJD. The methodology for the early identification of students at risk for failure in a professional degree program. Curr Pharm Teach Learn. 2014;6(6):798-806.

3. Alston GL, Battise DM, Neville MW. A 10-year study of the academic progress of students identified as low performers after their first semester of pharmacy school. Am J Pharm Educ.

2016;80(7):Article 118.

4. Schauner S, Hardinger KL, Graham MR, Garavalia L. Admission variables predictive of academic struggle in a PharmD program. Am J Pharm Educ. 2013;77(1):Article 8.

5. McCall KL, MacLaughlin EJ, Fike DS, Ruiz B. Preadmission predictors of PharmD graduates' performance on the NAPLEX. Am J Pharm Educ. 2007;71(1):Article 5.

6. Steinberg M, Morin AK. The impact of prematriculation admission characteristics on graduation rates in an accelerated Doctor of Pharmacy program. Am J Pharm Educ. 2015; 79(8):Article 118.

7. Poirier TI, Kerr TM, Phelps SJ. Academic progression and retention policies of colleges and schools of pharmacy. Am J Pharm Educ. 2013;77(2):Article 25.

8. Ferrante AB, Lambert J, Leggas M, Black EP. Predicting student success using in-program monitoring. Am J Pharm Educ.

2017;81(6):Article 111.

9. Chisholm MA. Students performance throughout the professional curriculum and the influence of achieving a prior degree. Am J Pharm Educ. 2001;65(4):350-354.

10. McCall KL, Allen DD, Fike DS. Predictors of academic success in a doctor of pharmacy program. Am J Pharm Educ.

2006;70(5):Article 106.

11. Sansgiry SS, Kawatkar AA, Dutta AP, Bhosle MJ. Predictors of academic performance at two universities: the effects of academic progression. Am J Pharm Educ. 2004;68(4):Article 103.

12. Cor MK, Brocks DR. Examining the relationship between prerequisite grades and types of academic performance in pharmacy school. Curr Pharm Teach Learn. 2018;10(6):695-700.

13. Maize DF, Fuller SH, Hritcko PM, et al. A review of remediation programs in pharmacy and other health professions. Am J Pharm Educ. 2010;74(2):Article 25.

14. Allen RE, Diaz C, Jr. Use of preadmission criteria and performance in the doctor of pharmacy program to predict success on the North American Pharmacists Licensure Examination. Am J Pharm Educ. 2013;77(9):Article193.

15. National Association of Boards of Pharmacy. North American Pharmacist Licensure Examination passing rates for 2015-2017 graduates per pharmacy school. https://nabp.pharmacy/wp-content/ uploads/2018/02/NAPLEX-Pass-Rates-2017.pdf. Accessed February $1,2019$.

16. Madden MM, Etzler FM, Schweiger T, Bell HS. The impact of pharmacy students' remediation status on NAPLEX first-time pass rates. Am J Pharm Educ. 2012;76(10): Article 191.

17. Beall WJ, DeHart MR, Riggs MR, Hensley J. Perceived stress, stressors, and coping mechanisms among Doctor of Pharmacy students. Pharmacy. 2015;3:344-354.

18. Benshoff JM, Cashwell CS, Rowell PC. Graduate students on campus: needs and implications for college counselors. J College Counseling. 2015;18(1):82-94.

19. Golde CM. Beginning graduate school: explaining first-year doctoral attrition. New Directions Higher Educ. 1998;101:55-64. https://doi.org/10.1002/he.10105

20. Sansgiry SS, Sail K. Effect of students' perceptions of course load on test anxiety. Am J Pharm Educ. 2006;70(2):Article 26. 


\section{American Journal of Pharmaceutical Education 2020; 84 (2) Article 7561.}

21. Smith L, Krass I, Sainsbury E, Rose G. Pharmacy students' approaches to learning in undergraduate and graduate entry programs. Am J Pharm Educ. 2010;74(6):Article 106.

22. Payakachat N, Gubbins PO, Ragland D, et al. Academic helpseeking behavior among student pharmacists. Am J Pharm Educ. 2013;77(1):Article 7.

23. Fjortoft N. Self-assessment in pharmacy education. Am J Pharm Educ. 2006;70(3):Article 64.

24. Stamper BD, Buhler AV, Harrelson JP, et al. Forecasting

academic success through implementation of an online prerequisite review tutorials program for first year pharmacy students. Curr Pharm Teach Learn. 2017;9:261-271.

25. Raub JN, Fiorvento A, Franckowiak TM, Wood T, Gortney JS. Implementing and sustaining a mentorship program at a college of pharmacy: the keys to successful mentorship. Curr Pharm Teach Learn. 2017;9:296-301.

26. Smith KJ, Grundmann O, Li RM. The development and impact of active learning strategies on self-confidence in a newly designed first-year self-care pharmacy course - outcomes and experiences. Curr Pharm Teach Learn. 2018:10;499-504. 